\title{
The effect of meal-feeding and food restriction on body composition, food utilization and intestinal adaptation in light-breed chicks
}

\author{
BY ZAFRIRA NITSAN \\ Institute of Animal Science, Agricultural Research Organization, The Volcani Center, \\ PO Box 6, Bet Dagan 50-200, Israel \\ AND I. NIR AND I. PETIHI \\ Department of Animal Science, Faculty of Agriculture, The Hebrew University of \\ Jerusalem, PO Box 12, Rehovot 76-100, Israel
}

\section{(Received 7 February 1983 - Accepted 3 August 1983)}

1. The effects of feeding meals, in amounts equivalent to ad lib. intake or to $75 \%$ and $50 \%$ restriction by intubation, were studied in chicks.

2. Growth estimated by body-weight gain and shank length was improved by tube feeding in the $50 \%$-restricted chicks.

3. Tube feeding increased energy retention at all feeding levels and nitrogen retention in the restricted chicks only.

4. Body fat was increased in the full-fed chicks by intubation and decreased in the $50 \%$-restricted chicks only.

5. Crop and gizzard weights were increased by food restriction and by intubation. Tube-feeding increased the weight of the small intestine at all feeding levels.

6. The activities of the digestive enzymes were lower in the pancreas and higher in the small intestine of the tube-fed chicks than in the voluntarily-fed ones at all feeding levels.

7. It is suggested that synthesis, secretion and stablity of the different pancreatic enzymes could be affected diversely by feeding regimens.

Restricted feeding is associated with periods of intense feeding and periods of feed deprivation. The effects of periodic feeding or meal-eating were first studied with pigeons (von Seeland, 1887) and salamanders (Margulis, 1913). More recent studies have utilized chickens (Lepkovsky et al. 1960; Cohn et al. 1961; Feigenbaum et al. 1962; Griminger et al. 1969). A review of classical work in this area has been presented by Fabry (1967). Intubation of two meals per d, an amount of food equal to that consumed by ad lib.-fed chicks, increased metabolizable energy, body fat and energy utilization but decreased nitrogen retention without affecting body-weight gain (Nir et al. 1979). It was postulated that the previously-described effects could be due partly to a slower passage of the food through the gastrointestinal (GI) tract and, therefore, to a longer exposure of the food to chemical, physical and microbiological alterations. The longer stay of the food in the GI tract could have caused a full sensation which reduced the activity of the tube-fed birds and improved energy retention.

Light-bodied chicks exposed to intermittent feeding (fed every second day) consumed about $80 \%$ the amount of ad lib.-fed chicks. They were able to maintain a body composition similar to that of the ad lib.-fed controls (Nir \& Nitsan, 1979). In chickens of a heavy breed, a similar restriction caused a marked reduction of body fat (Simon \& Blum, 1972). It seems that the strategy of the light-breed chicks is to maintain a normal body composition and to reduce growth rate, when food restriction is moderate.

Among the GI organs, only the crop weight was significantly increased by tube-feeding, as compared with ad lib. feeding. The activity of the digestive enzymes in the small intestine corresponded to the amounts of the intestinal contents. The purpose of the present work was to study the combined effects of food restriction and meal-feeding. 
Light-breed chicks were exposed to different levels of food restriction, in order to estimate up to what extent of restriction they were able to maintain their body composition. In addition, meal-feeding was accentuated by pair-feeding chicks by the tube technique. The amount of food consumed by groups fed ad lib. or restricted, was pair-fed to parallel groups in two meals per $d$ by the tube-feeding technique.

\section{EXPER IMENTAL}

\section{Animals and diets}

New Hampshire $\times$ White Leghorn male chicks ( 2 weeks old) were divided into seven equal groups of similar mean body-weight (ten chicks per group). They were identified with wing bands and kept in colony cages with raised wire floors. The chicks received proprietary starter crumbs (calculated $210 \mathrm{~g}$ crude protein $/ \mathrm{kg}$ and $12.5 \mathrm{MJ} \mathrm{ME} / \mathrm{kg}$ ). The room was illuminated continuously. Two groups were fed ad lib. $\left(V_{100}\right)$ and had free access to food and water. The food intake of each group was measured daily. One group of the restricted-feed chicks was given $75 \%\left(V_{75}\right)$ and one group $50 \%\left(V_{50}\right)$ of the average amount consumed by the ad lib.-fed chicks the previous day. Three groups of chicks were fed by intubation into the crop twice daily (at 08.00 and 19.00 hours); these groups $\left(T_{100}, T_{75}\right.$ and $\left.T_{50}\right)$ were pair-fed to $V_{100}, V_{75}$ and $V_{50}$ respectively. The food was mixed with warm water (4 parts food : 6 parts water, w/w), and intubated as described by Nir et al. (1979). Half the average amount consumed by the $V_{100}$ or by the $V_{75}$ and $V_{50}$ chicks respectively was given in each meal. This was done by weighing the tube-fed chicks before, during and after intubation. Variations from the amounts designed were corrected at the following meal. The total amount of food intubated during the experimental period varied from the designed amount by $1 \mathrm{~g} /$ chick.

All the chicks were killed following $14 \mathrm{~d}$, starting at 10.00 hours, $2 \mathrm{~h}$ after the last meal. The chicks were killed sequentially, one chick from each group. The autopsy of each chick lasted about $6 \mathrm{~min}$. Autopsy, chemical analyses and determination of activities of digestive enzymes were carried out as described earlier (Nir \& Nitsan, 1979; Nitsan et al. 1974). Enzyme activities were expressed in units, 1 unit being defined as a change of $10^{-3}$ absorbance units for trypsin, chymotrypsin and amylase under the conditions specified for each assay system, using $12.7 \mathrm{~mm}$ Bausch and Lomb test tubes. Lipase units were defined as $\mathrm{g}\left(\times 10^{-2}\right)$ naphthol released $/ 10 \mathrm{~min}$ at $37^{\circ}$.

Statistical analysis was performed as described by Snedecor \& Cochran (1967) by Newman's $Q$ test, the significances of main effects and of interactions being assayed by the $F$ test.

\section{RESULTS}

\section{Body-weight gain, body composition and food utilization (Table 1)}

Body-weight gain and linear growth (shank length) were decreased by feed restriction. Tube feeding increased body-weight gain in the $50 \%$-restricted chicks only. Linear growth was increased by tube feeding; this increase was highest in the $50 \%$-restricted chicks.

In the voluntarily-fed chicks, carcass dry matter and fat concentration were reduced in the $V_{50}$ chicks only. The effect of tube feeding on carcass dry matter and fat concentration varied in the different feeding levels: while these measurements were increased markedly in the $T_{100}$, no effect was observed in the $T_{75}$ and $T_{50}$ chicks. $\mathrm{N}$ and ash concentrations in the carcass were negatively related to dry matter and fat concentrations.

Since food intake was not measured individually in the voluntarily-fed chicks, no statistical analysis could be conducted on energy and protein retention. Energy and N retention were reduced parallel to the extent of feed restriction. Tube feeding improved energy retention, the improvement being intensified as the restriction increased. $\mathrm{N}$ retention was decreased by tube feeding in the $T_{100}$ chicks and improved in the restricted ones. 
Meal-feeding in food-restricted chicks

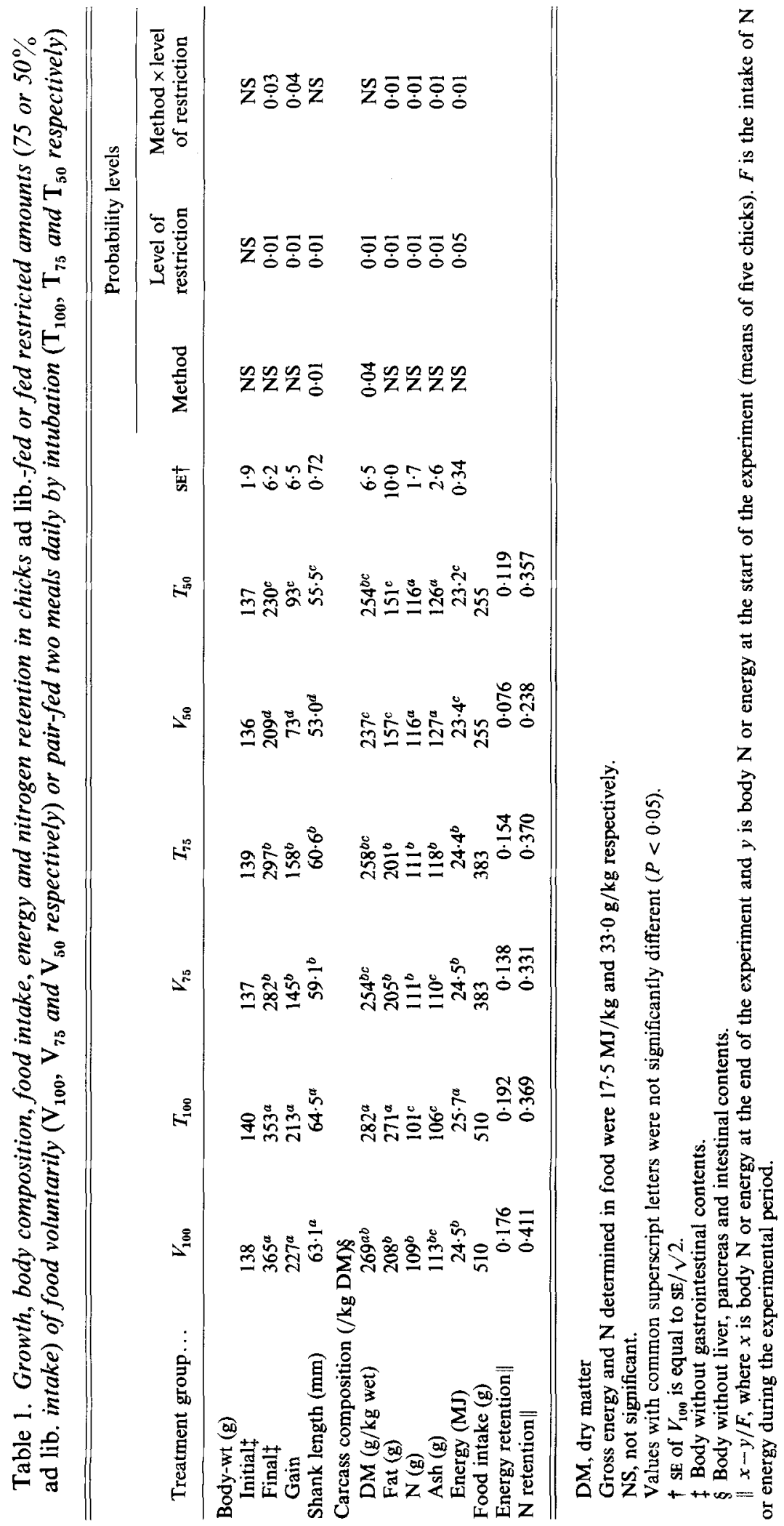


Zafrira Nitsan, I. Nir and I. Petihi

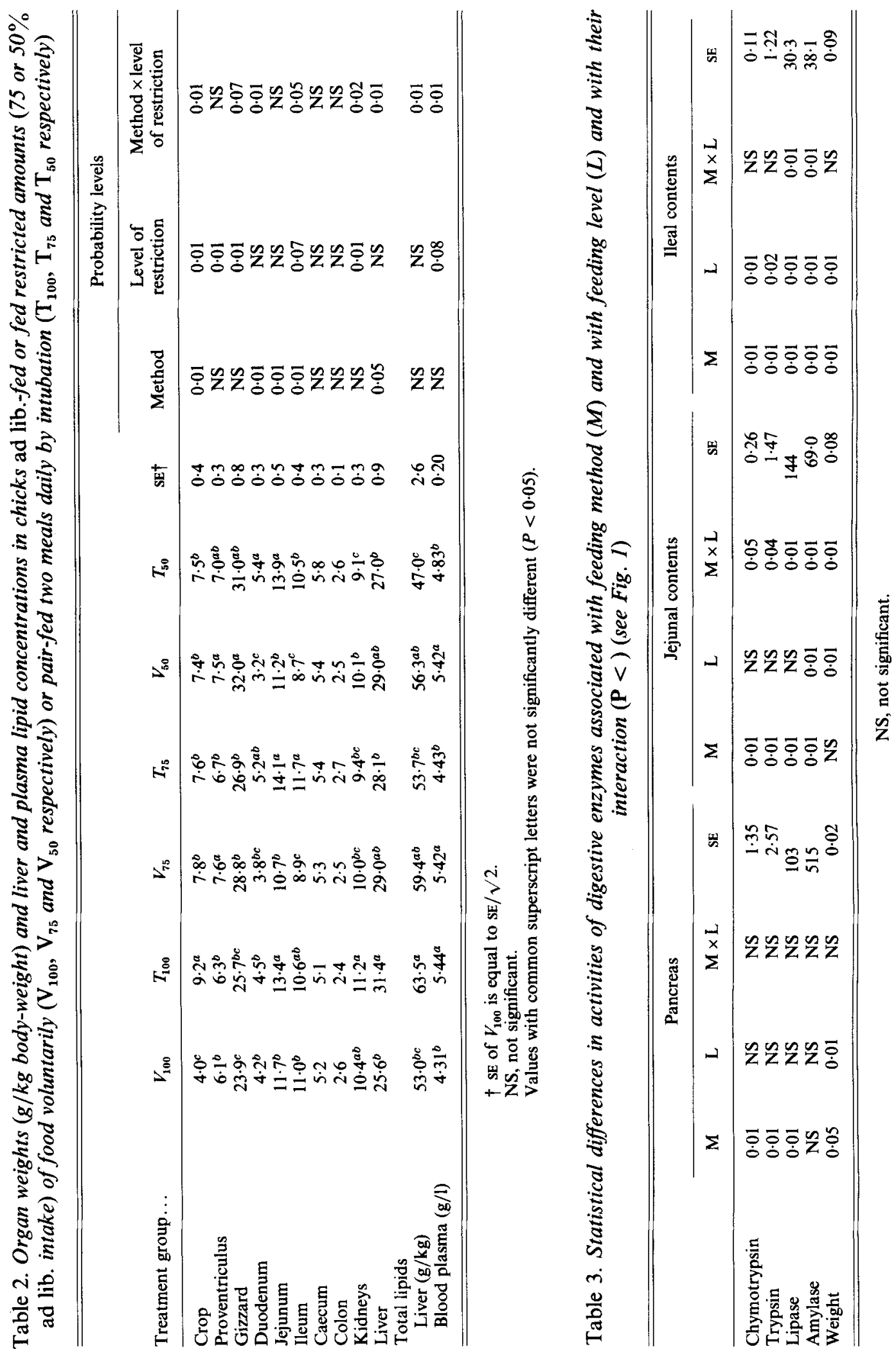




\section{Organ weight, blood and liver fat concentration (Table 2)}

Tube-feeding increased the relative weight of the crop by more than twofold in the full-fed chicks only $\left(T_{100}>V_{100}\right)$. In the restricted groups its relative weight was about twofold that of the $V_{100}$ group and tube-feeding had no effect in this respect. Proventriculus and gizzard relative weights increased in the restricted-fed groups. Tube-feeding had no effect on these factors. While the duodenum and jejunum relative weight was increased by tube-feeding,

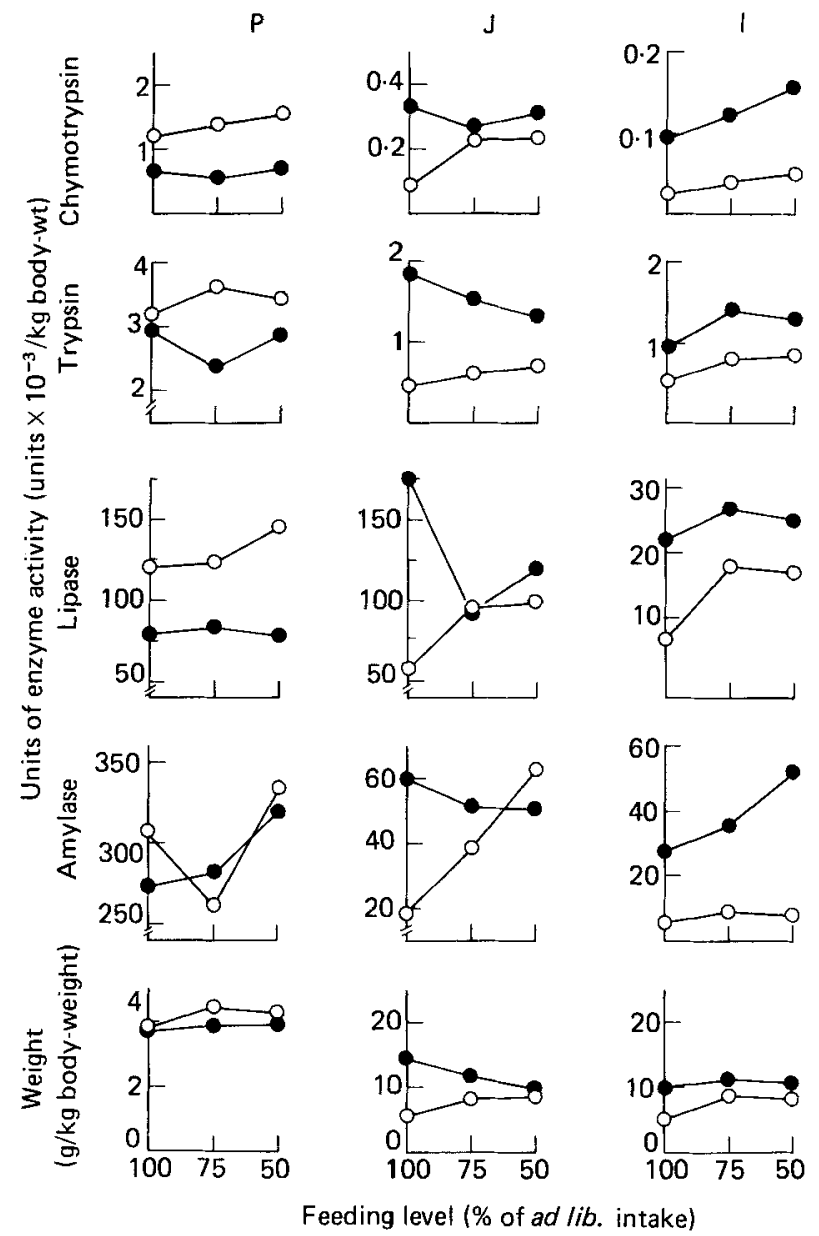

Fig. 1. Weight of pancreas (P), jejunal (J) and ileal (I) contents (g/kg body-weight) and the activities of digestive enzymes (units $\times 10^{-2}$ ) in the respective sites of chicks ad lib.-fed or restricted to 75 and $50 \%$ of the $a d$ lib. intake voluntarily $(O)$ or by intubation $(O)$ twice daily. Statistical analysis presented in Table 3.

but not by feed restriction, the ileum relative weight was depressed in the $V_{75}$ and $V_{50}$ groups and increased by the tube-feeding. This increase was found in the $T_{75}$ and $T_{50}$ but not in the $T_{100}$ chicks. In the ad lib.-fed chicks, the ratio jejunum :ileum weight was $1 \cdot 16$; it increased in the $T_{100}$ chicks to 1.26. In the restricted chicks the value for this ratio was 1.2 and 1.3 in the $V_{75}$ and $V_{50}$ groups respectively without an additive effect of tube-feeding.

Caecum and colon relative weights were not affected by feed restriction or by tube-feeding. Liver weight, liver and blood plasma lipids were increased by tube-feeding in the $T_{100}$ chicks only. In the restricted-fed chicks these factors tended to decrease with tube-feeding. 
Kidney relative weight was not affected by feed restriction in the voluntarily-fed groups. Tube-feeding decreased the kidneys' weight in the restricted-fed chicks (statistically significant for the $T_{50}$ group).

Pancreas weight, intestinal content and activity of digestive enzymes (Fig. 1, Table 3) The relative weight of the pancreas was slightly increased by feed restriction and decreased by tube-feeding. In chicks fed voluntarily, the jejunal and ileal contents were increased by feed restriction. Tube-feeding increased the relative weight of the jejunal and ileal contents. The effect of tube-feeding on jejunal content (but not on ileal content) was negatively related to the extent of restriction. This could also be expressed by the ratio, jejunal :ileal contents, which was about 1 in all the voluntarily-fed and restricted tube-fed groups but attained a value of 1.9 in the $T_{100}$ chicks.

Activities of pancreas enzymes (amylase excepted) were lower in the tube-fed groups than in the voluntarily-fed ones. The feeding level had no significant effect in this respect. The effect of tube-feeding or amount of restriction on pancreatic amylase activity was not consistent.

The overall effect of tube feeding on the enzymes' total activity in the two parts of the small intestine was an increase as compared with the voluntarily-fed birds (Fig. 1); in the jejunum, their activity was higher than in the ileum. In the voluntarily-fed chicks, the activity of the enzymes in the jejunum and the ileum increased with feed restriction. The same was found for the tube-fed birds in the ileum but not in the jejunum.

\section{DISCUSSION}

\section{Body-weight gain and composition and energy and nitrogen utilization}

Intubation of the same amount of food consumed voluntarily caused a consistent increase in energy utilization, but the diversion of energy to fat or lean tissue varied according to the feeding level. When tube-fed the amount consumed ad lib. $\left(T_{100}\right)$, the excess of available energy was diverted to body fat (Table 1). This finding confirms previous information on tube-fed chicks (Nir et al. 1979) and meal-fed rats (Fabry, 1967).

In the $T_{75}$ and $T_{50}$ chicks, the excess of available energy was probably diverted to lean tissue formation since their carcasses did not contain more fat than their voluntarily-fed counterparts. It seems that the contribution of tube-feeding to energy retention increases with the extent of feed restriction. While the tube-feeding increased energy retention by $9 \%$ in the $T_{100}$ birds, this improvement was $12 \%$ and $56 \%$ in the $T_{75}$ and $T_{50}$ chicks respectively. The improved energy retention was concomitant to $\mathrm{N}$ retention in the restricted groups. The reduced variation in growth rate of the tube-fed chicks could also contribute to the improvement in energy retention. In the tube-fed chicks the coefficient of variation (cv) for the final body-weight was $2 \cdot 7,4.6$ and 4.3 for the $T_{100}, T_{75}$ and $T_{50}$ birds respectively. For .the voluntarily-fed chicks, these values were $4 \cdot 9,6.7$ and $19 \cdot 4$ for $V_{100}, V_{75}$ and $V_{50}$ birds respectively. With tube-feeding, two major sources of variation, appetite and competition for food, were abolished. The cv increased markedly with the extent of restriction in the voluntarily-fed groups, as feed restriction increased competition for food. The remaining sources of variation found in the tube-fed chicks were quite similar at the different feeding levels. This remaining variation was apparently due to unidentified factors which, despite their quantitative similarity at all tube-feeding levels, were not necessarily identical. $\mathrm{N}$ retention in the voluntarily-fed chicks decreased with feed restriction due to utilization of part of the dietary protein as energy source. Improvement of energy utilization by the restricted tube-fed chicks probably decreased the diversion of dietary protein to energy and hence improved protein retention.

This work confirms an earlier finding (Nir \& Nitsan, 1979) that with up to $75 \%$ restriction, 
the strategy of light-breed chicks is to maintain a body composition similar to ad lib.-fed chicks at the expense of growth. At $50 \%$ restriction, in the present work, body fat concentration decreased. The critical feeding level under which body composition is still maintained in light-breed chicks is yet to be determined.

The importance of the gut microflora in digestion and absorption (Coates, 1976) can aid in the understanding of the response of chickens to meal-feeding. Meal-feeding reduced the bacterial count $/ \mathrm{g}$ intestinal chyme and also probably changed its composition, since ad lib.-fed chicks responded differently to dietary supplementation of neomycin sulphate than meal-fed counterparts (Z. Nitsan and I. Nir, unpublished results).

\section{Organ weights}

Feed restriction drives the voluntarily-fed birds to consume the daily ration during a short period. This is concomitant with the increase in weight of the storage organs, mainly the crop and the gizzard. However, intestinal segment size was associated with the total amount of food consumed, as it was smaller in the restricted birds than in the ad lib.-fed ones. Tube-feeding of equal amounts affected the storage organs similarly, but also increased the weight of the intestinal segments. The tube-fed chicks were offered their daily ration in two meals. Learned anticipatory control could cause acceleration of gastric emptying to the fore intestine in order to evacuate food from the storage organs before the expected meal. Enlargement of the intestine was also obtained in overfed chicks (Nitsan et al. 1974). In the present study, the mash for the tube-fed chicks was finely-ground and mixed with water. According to Patrick \& Schaible (1980), the rate of passage of food through the GI tract is accelerated by the amount of food consumed and by the size of the particles. Heuser (1945) stated that wet mash passes from the crop faster than dry mash. Since in meal-fed birds the passage of the food through the whole GI tract (determined by using ferric oxide as an indicator) was not accelerated (Z. Nitsan and I. Nir, unpublished results), the rapid passage of the food from the crop to the small intestine occurred concurrently with an accumulation of chyme, exceeding the normal capacity of the small intestine and causing its enlargement. The regulation of gastric emptying was discussed by Hunt \& Knox (1968) and the constraints of the GI tract by Booth (1979).

The kidneys' weight reflected $\mathrm{N}$ excretion: it was increased by tube-feeding in the $T_{100}$ birds and decreased in the $T_{75}$ and $T_{50}$ birds, parallel to $\mathrm{N}$ retention.

The liver's relative weight, its fat concentration and blood plasma lipids reflected the enchanced lipogenesis caused by tube-feeding (or meal-feeding) in the $T_{100}$ birds, as reported earlier (Nir et al. 1979). An opposite effect of tube-feeding, not significant for liver weight but statistically significant for liver and plasma lipids, was found in the restricted-fed birds. Food restriction is concurrent to meal-feeding and meal-feeding increases lipogenesis (Leveille et al. 1975). Assuming that lipogenesis is affected by the size of the meal, it is suggested that in the tube-fed restricted birds which received their daily ration in two meals, lipogenesis was lower than in the voluntarily-restricted birds which were provided with one meal per day.

\section{Activity of digestive enzymes}

The higher amount of intestinal chyme in the tube-fed birds triggered a greater release of digestive enzymes from the pancreas into the intestine. This resulted in a lower pancreatic weight and enzymic activities (Fig. 1). The same results were observed in overfed birds (Nitsan et al. 1974). This cofirms previous studies which showed that any alteration in the type or quantity of the diet (i.e. substrates) leads to an adjustment of specific and total enzyme activities in the pancreatic tissue and in the pancreatic juice (Snook, 1968; Hulan \& Bird, 1972; Corring, 1980).

In order to evaluate whether the treatments affected differentially the levels of the various 

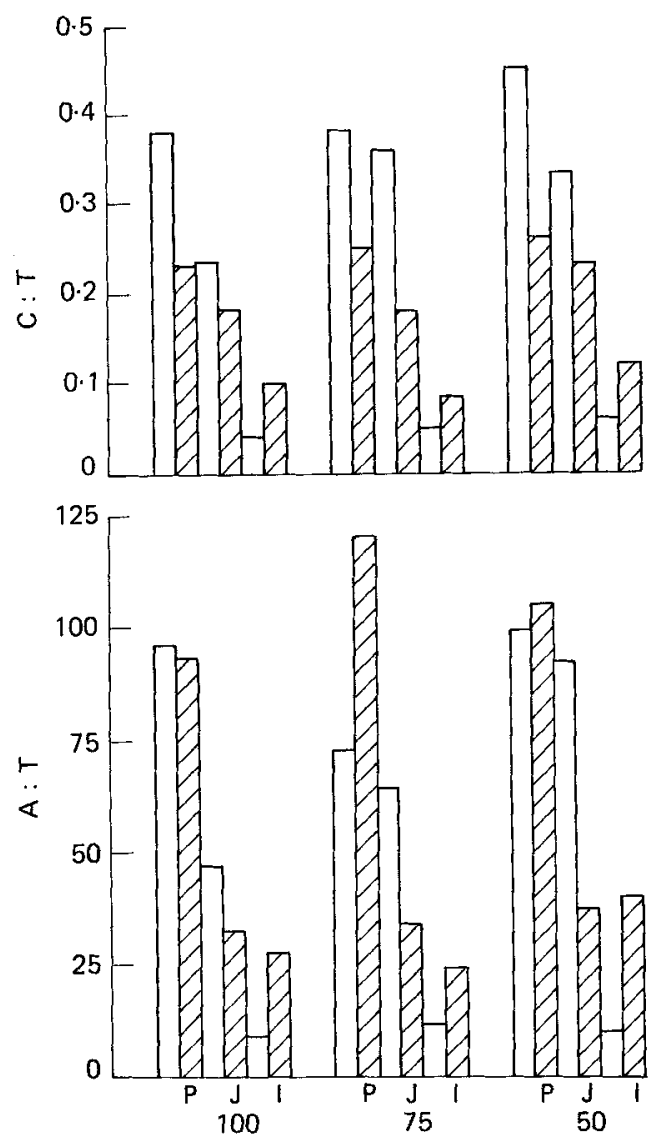

Feeding level (\% of ad /ib. intake)

Fig. 2. The ratios, amylase : tryspin $(A: T)$ and chymotrypsin : trypsin $(C: T)$ in the pancreas $(P)$, jejunum (J) and ileum (I) of chicks ad lib.-fed or restricted to 75 and $50 \%$ of the ad lib. intake, voluntarily ( $\square$ ) or by intubation (国) twice daily.

Probability levels of feeding method:

\begin{tabular}{|c|c|c|c|c|c|}
\hline \multicolumn{2}{|c|}{$P$} & \multicolumn{2}{|c|}{$\mathbf{J}$} & \multicolumn{2}{|c|}{ I } \\
\hline$P<$ & $\mathrm{SE}$ & $P<$ & $\mathbf{S E}$ & $P<$ & SE \\
\hline 0.07 & $6 \cdot 14$ & $0 \cdot 01$ & $8 \cdot 13$ & 0.05 & $5 \cdot 21$ \\
\hline 0.01 & 0.04 & 0.01 & 0.03 & NS & 0.023 \\
\hline
\end{tabular}

NS, not significant. The effects of feeding level and interaction method $\times$ feeding level were not significant.

enzyme activities, resulting from selective synthesis, secretion and/or disappearance, the activities of the amylase and chymotrypsin in the pancreas, jejunum and ileum were calculated as related to the trypsin activity at the same site (Fig. 2). Trypsin appeared to be more stable in the small intestine, as compared with the other digestive enzymes, since it was the only enzyme whose activity in the ileum was close to that found in the jejunum (Fig. 1). It was reported that pancreatic amylase is destroyed by bacterial action in the alimentary tract of chickens (Lepkovsky et al. 1964).

The ratio for lipase :trypsin was not estimated, since the source of lipase activity is not the pancreas alone but also the bile. The contribution of salivary amylase to intestinal amylase is negligible (Nitsan \& Madar, 1978). 
In all treatments, the ratios, amylase : trypsin $(\mathrm{A}: \mathrm{T})$ and chymotrypsin : trypsin $(\mathrm{C}: \mathrm{T})$ decreased from the pancreas to the jejunum, and decreased further in the ileum. In the feed-restricted voluntarily-fed chicks, A :T and C:T were similar to those found in the $V_{100}$ chicks. In the tube-fed chicks, $\mathrm{C}: \mathrm{T}$ was lower than in voluntarily-fed chicks, in the pancreas and the jejunum, but higher in the ileum, at all feeding levels.

Tube-feeding increased A:T in the pancreas of the restricted-fed chicks. In the two segments of the intestine, this ratio followed the same trend as was obtained for C:T. There is much evidence that in different species, changes in diet composition are concurrent to a 'purposive adaptation' of pancreatic enzyme secretion (Hulan \& Bird, 1972). In the present work, it was found that synthesis, secretion and/or stability of the pancreatic enzymes can also be affected differently by feeding regimen.

This research was supported by grant no. I-89-79 from the US-Israel Binational Agricultural Research and Development Fund (BARD). Contribution no. 628-E, 1982 series, from the Agricultural Research Organization, The Volcani Center.

\section{REFERENCES}

Booth, D. A. (1979). In Food Intake Regulation in Poultry, pp. 13-62 [K. M. Boorman and B. M. Freeman, editors]. Edinburgh: British Poultry Science Ltd.

Coates, M. (1976). In Digestion in the Fowl, pp. 179-191 [K. M. Boorman and B. M. Freeman, editors]. Edinburgh: British Poultry Science Ltd.

Cohn, C., Pick, R. \& Katz, L. (1961). Circulation Research 1, 139-145.

Corring, T. (1980). Reproduction, Nutrition and Development 20, 1217-1235.

Fabry, P. (1967). In Handbook of Physiology, sect. 6, vol. 1, pp. 31-49 [C. F. Code and W. Heidel, editors]. Washington, DC: American Physiological Society.

Feigenbaum, A. S., Fisher, H. \& Weiss, H. S. (1962). American Journal of Clinical Nutrition 11, $312-316$.

Griminger, P., Villamil, V. \& Fisher, H. (1969). Journal of Nutrtion 99, 368-374.

Heuser, G. F. (1945). Poultry Science 24, $20-24$.

Hulan, W. H. \& Bird, F. H. (1972). Journal of Nutrition 102, 459-468.

Hunt, J. N. \& Knox, M. T. (1968). In Handbook of Physiology, sect. 6. vol. 4, pp. 1917-1935 [C. F. Code and W. Heidel, editors]. Washington, DC: American Physiological Society.

Lepkovsky, S., Chari-Briton, A., Lemmon, R. M., Ostwald, R. C. \& Dimick, M. K. (1960). Poultry Science 39, 385-389.

Lepkovsky, S., Wagner, M., Furuta, F., Ozone, K. \& Koike, T. (1964). Poultry Science 43, 722-733.

Leveille, G. A., Romsos, D. R., Yen, Y. Y. \& O'Hea, E. K. (1975). Poultry Science 54, $1075-1093$.

Margulis, S. (1913). American Naturalist 47, 477-487.

Nir, I. \& Nitsan, Z. (1979). British Poultry Science 20, 61-74.

Nir, I., Petihi, I. \& Nitsan, Z. (1979). In Food Intake Regulation in Poultry, pp. 391-404 [K. M. Boorman and B. M. Freeman, editors]. Edinburgh: British Poultry Science Ltd.

Nir, I., Shapira, N., Nitsan, Z. \& Dror, Y. (1974). British Journal of Nutrition 32, 229-239.

Nitsan, Z., Dror, Y., Nir, I. \& Shapira, N. (1974). British Journal of Nutrition 32, 241-247.

Nitsan, Z. \& Madar, Z. (1978). British Journal of Nutrition 40, 235-242.

Patrick, H. \& Schaible, P. J. (1980). Poultry: Feeds and Nutrition. Westport, CT: AVI Publishing Company, Inc. Simon, J. \& Blum, J. C. (1972). Canadian Journal of Physiology and Pharmacology 50, 634-644.

Snedecor, G. H. \& Cochran, W. C. (1967). Statistical Methods, 6th ed. Ames, Iowa: Iowa State University.

Snook, J. T. (1968). Journal of Nutrition 94, 351-360.

von Seeland, J. (1887). Biologisches Zentralblatt 7, 145-158. 